\title{
Necrotizing Enterocolitis Is Associated With Ureaplasma Colonization in Preterm Infants
}

\author{
ADORA C. OKOGBULE-WONODI, GEORGE W. GROSS, CHEN-CHIH J. SUN, ALEXANDER G. AGTHE, LI XIAO,
} KEN B. WAITES, AND ROSE MARIE VISCARDI

\begin{abstract}
Departments of Pediatrics [A.C.O.-W., A.G.A., R.M.V.], Radiology [G.W.G.], and Pathology [C.-C.J.S.], University of Maryland School of Medicine, Baltimore, Maryland 21201; Department of Pathology [L.X., K.B.W.], University of Alabama at Birmingham,
\end{abstract}

Birmingham, Alabama 35249

\begin{abstract}
The study objective was to determine whether Ureaplasma respiratory tract colonization of preterm infants $<33 \mathrm{wk}$ gestation is associated with an increased risk for necrotizing enterocolitis (NEC). One or more tracheal or nasopharyngeal aspirates for Ureaplasma culture and PCR were obtained during the first week of life from 368 infants <33 wk gestation enrolled from 1999 to 2003 or from 2007 to 2009. NEC Bell stage $\geq 2$ was confirmed by radiological criteria, and pathology, if available. Cord serum samples were analyzed for IL- 6 and IL- $1 \beta$ concentrations, and placentas were reviewed for histological chorioamnionitis in the first cohort. NEC was confirmed in 29 of $368(7.9 \%)$ of the combined cohorts. The incidence of NEC was 2.2-fold higher in Ureaplasma-positive $(12.3 \%)$ than Ureaplasma-negative $(5.5 \%)$ infants $<33$ wk (OR, 2.43; 95\% CI, 1.13-5.2; $p=0.023$ ) and 3.3-fold higher in Ureaplasma-positive $(14.6 \%)$ than Ureaplasma-negative $(4.4 \%)$ infants $\leq 28$ wk (OR, 3.67; 95\% CI, 1.36-9.93; $p=0.01)$. Age of onset, hematologic parameters at onset, and NEC severity were similar between Ureaplasma-positive and negative infants. Cord serum IL-6 and IL- $1 \beta$ concentrations were significantly higher in Ureaplasmapositive than in Ureaplasma-negative NEC-affected infants. Ureaplasma may be a factor in NEC pathogenesis in preterm infants by contributing to intestinal mucosal injury and/or altering systemic or local immune responses. (Pediatr Res 69: 442-447, 2011)
\end{abstract}

$\mathrm{N}$ ecrotizing enterocolitis (NEC), a gastrointestinal emergency, affects $\sim 5$ to $10 \%$ of very LBW (VLBW) infants. It is a devastating disease with mortality as high as $30 \%$. Prematurity is the greatest risk factor for development of NEC $(1,2)$. Several studies suggest that the initiation of an intense systemic and local inflammatory cascade leads to intestinal necrosis in response to inciting risk factors (3-8).

Ureaplasma parvum and Ureaplasma urealyticum are commensals of the genital tract of $40-80 \%$ childbearing aged women $(9,10)$ and are the most common organisms isolated from infected amniotic fluid and placentas (11). Infertility, chorioamnionitis, preterm delivery, and morbidity such as bronchopulmonary dysplasia (BPD) have all been associated with perinatal Ureaplasma infection (12). The organisms elicit both systemic and local host inflammatory responses in hu-

Received September 7, 2010; accepted November 20, 2010.

Correspondence: Rose Marie Viscardi, M.D., Department of Pediatrics/Neonatology, 29 S. Greene Street, Suite GS 110, Baltimore, MD 21201; e-mail: rviscard@ umaryland.edu

Supported by grants HL71113, HL087166, and 5RO1A1072577 from the National Institutes of Health. mans $(13,14)$ and in cell $(15)$ and animal models $(16-18)$. The intestinal and respiratory tracts are directly exposed to infected amniotic fluid containing inflammatory mediators, which could enhance the inflammatory response to certain bacteria and their products. In addition to being isolated from the respiratory tract, Ureaplasma has been detected in gastric aspirates by culture (19-21) and molecular methods (22) and in rectal cultures (21). The effects of such synergistic inflammatory interactions could be potentially detrimental to the preterm host leading to a compromised intestinal barrier with development of diseases such as NEC and gastrointestinalrelated sepsis.

Although preterm respiratory colonization with Ureaplasma is a known risk factor for neonatal morbidities, its association with NEC has not been previously determined. We hypothesized that preterm infants exposed to Ureaplasma spp. in utero or colonized at birth are at increased risk for NEC. To evaluate the relationship of Ureaplasma colonization with NEC, we examined the incidence and associated clinical and inflammatory variables of NEC in two prospectively recruited cohorts of preterm infants with Ureaplasma colonization status during the first week of life confirmed by culture and PCR who were born at GA $<33$ wk and birth weight $<1501 \mathrm{~g}$.

\section{METHODS}

Sample. Infants born at GA $<33$ wk and birth weight $<1501 \mathrm{~g}$ admitted to the NICUs at the University of Maryland Medical Center and Mercy Medical Center (Baltimore, MD) were eligible for study participation. We enrolled patients in two studies designed to characterize the effects of Ureaplasma on preterm infant outcomes from 1999 to 2003 [cohort 1; details of this cohort have been previously reported $(23,24)]$ and from 2007 to 2009 (cohort 2). The objective of the first study was to determine the incidence of invasive disease with $U$. parvum and $U$. urealyticum and the relationship with adverse outcomes in VLBW infants. The objective for the current study is to analyze potential single nucleotide polymorphisms in relevant toll-like receptor genes associated with risk for Ureaplasma respiratory tract colonization and BPD. For both studies, infants were excluded if they had confirmed diagnoses of congenital brain/neural tube defects or congenital viral infections. Parental consent was obtained, and the institutional review boards of both institutions approved the study protocols.

NEC assessment. Cases of stage $\geq 2$ NEC according to the modified Bell criteria $(1,25)$ were confirmed by typical radiological findings (pneumatosis intestinalis, portal venous air, pneumoperitoneum, and/or fixed intestinal loop) and/or pathology, if available, and were classified as medical or surgical

Abbreviations: BPD, bronchopulmonary dysplasia; NEC, necrotizing enterocolitis; VLBW, very LBW 
NEC. A radiologist blinded to Ureaplasma culture status reviewed all abdominal radiographs of suspected NEC cases. Cases that were confirmed by pathological examination as spontaneous intestinal perforation $(n=2)$ were excluded. Postnatal age, presence or absence of feeding, and white blood cell and absolute neutrophil counts at birth and onset of NEC were recorded.

Ureaplasma detection. One or more tracheal or nasopharyngeal aspirates were obtained during the first week of life from enrolled infants. Samples were processed, 10-fold serially diluted in $10 \mathrm{~B}$ broth to $10^{-4}$ and incubated at $37^{\circ} \mathrm{C}$ in humidified $5 \% \mathrm{CO}_{2}$. Dilutions in which a color change occurred were inoculated on A8 agar and incubated at $37^{\circ} \mathrm{C}$ in humidified $5 \% \mathrm{CO}_{2}$ Cultures were examined daily for $1 \mathrm{wk}$ for color change or colonies typical of Ureaplasma (26). DNA was extracted from original tracheal aspirate or nasopharyngeal samples and culture-positive isolates using QiAmp DNA Blood Mini kits (Qiagen, Valencia, CA) according to the manufacturer's protocol. PCR for cohort 1 was performed as previously described with primers directed against the $5^{\prime}$ region of the multiple-banded antigen $(M B A)$ gene to identify all positive samples and primers targeting urease gene to identify species (24). For cohort 2, DNA samples were analyzed by multiplex real-time PCR to differentiate the two Ureaplasma species simultaneously as previously described using the Roche LightCycler 2.0 (27).

Serum cytokines. For the first cohort, cord serum samples were analyzed for IL- 6 and IL- $1 \beta$ in duplicate samples by standard two antibody ELISA using commercial antibody pairs and recombinant standards (Endogen, Boston, MA) as previously described (23). A curve fitted to standards was generated using a computer program (Softpro: Molecular Devices), and cytokine concentrations from each sample were calculated from the standard curve. Assay sensitivities were 1.5 and $0.78 \mathrm{pg} / \mathrm{mL}$ for IL-6 and IL- $1 \beta$, respectively.

Placental pathology. Placental studies were performed on 197 of 232 $(85 \%)$ subjects with confirmed Ureaplasma respiratory status of the firs cohort. Sections of umbilical cord, membrane roll, placental disc near the cord insertion site, and the midpoint between cord insertion and the periphery of the placental disc were formalin-fixed, paraffin-embedded, and hematoxylinand eosin-stained. A pathologist blinded to maternal and infant clinical status reviewed the sections. Histologic chorioamnionitis was separated into maternal and fetal involvement and a stage assigned based on the scheme proposed by Redline et al. (28). Fetal vasculitis was defined as polymorphonuclear infiltration of the chorionic vessels or umbilical cord (28).

Statistical analysis. The $t$ test and ANOVA was used to compare continuous normally distributed data and Mann-Whitney or Kruskal-Wallis test for nonnormally distributed data. The $\chi^{2}$ or Fisher exact test was used to compare categorical variables. Univariate ORs and 95\% CIs were calculated for all variables for NEC outcome. Analyses comparing Ureaplasma-positive and negative infants were stratified by NEC status. Statistical analysis was performed using STATA 7.0 (Stata Corp., College Station, TX). A $p<0.05$ was considered significant.

\section{RESULTS}

Study cohort characteristics. For cohort 1, NEC status was confirmed for 308 of 313 subjects, and Ureaplasma respiratory status was available on 232 of 308 (75\%). For cohort 2, of 324 infants $<33$ wks gestation who were eligible for the study, 20 were missed because of the lack of parental contact, 168 declined consent, and parental consent was obtained for the remaining 136 infants. NEC and Ureaplasma respiratory status were available for all cohort 2 enrolled subjects. The incidence of NEC was similar for both cohorts [cohort 1, 15/232 (6.5\%); cohort 2, 14/136 (10.3\%); $p=0.229$ ] and did not differ from the NEC rate for nonenrolled infants during the study periods. The combined NEC rate was 29 of 368 (7.9\%). Ureaplasma respiratory tract colonization rate was also similar for both cohorts [cohort 1,75/232 (32\%); cohort 2, 57/136 $(42 \%) ; p=0.064$ ] with an overall colonization rate of 132 of $368(36 \%)$. Ureaplasma parvum was the predominant species (67\%) compared with U. urealyticum (27\%). Both species were present in $6 \%$ specimens. For all subsequent analyses, the cohorts were combined.

Ureaplasma respiratory tract colonization and NEC in $V \boldsymbol{L B} \boldsymbol{W}$ infants. We first analyzed the relationship of demographic, antenatal, and early neonatal factors with NEC. In the combined cohorts, none of the factors included in analyses were significantly associated with NEC (Table 1). Specific details concerning feeding such as age when feedings were started, composition of feeds, or time to full feeds were not recorded. However, all infants were fed according to an established feeding protocol.

Ureaplasma-colonized infants were less mature and experienced a higher rate of preterm premature rupture of the membranes, maternal antibiotic exposure, and longer duration of mechanical ventilation but a lower rate of pregnancy-induced hypertension than noncolonized infants regardless of whether

Table 1. Association of clinical variables and NEC

\begin{tabular}{|c|c|c|c|c|}
\hline Variable & No NEC $(N=339)$ & $\operatorname{NEC}(N=29)$ & Unadjusted OR (95\% CI) & $p$ \\
\hline Birth weight $(\mathrm{g})$, mean $\pm \mathrm{SD}$ & $1021 \pm 352$ & $943 \pm 288$ & $0.999(0.998-1.00)$ & 0.247 \\
\hline $\mathrm{GA}(\mathrm{wk})$, mean $\pm \mathrm{SD}$ & $27.3 \pm 3.6$ & $27.1 \pm 2.2$ & $0.985(0.889-1.091)$ & 0.771 \\
\hline Females & $161(47.5)$ & $10(35)$ & $0.58(0.263-1.28)$ & 0.182 \\
\hline Black race & $229(67)$ & $21(72)$ & $1.61(0.59-4.413)$ & 0.351 \\
\hline POL & $266(79)$ & $21(72)$ & $0.711(0.302-1.671)$ & 0.433 \\
\hline PPROM & $145(43)$ & $13(45)$ & $1.09(0.507-2.33)$ & 0.830 \\
\hline Maternal antibiotics & $259(76)$ & $22(76)$ & $0.971(0.399-2.356)$ & 0.948 \\
\hline Cesarean section & $185(55)$ & $17(58)$ & $1.18(0.546-2.545)$ & 0.674 \\
\hline PDA & $174(52)$ & $12(43)$ & $0.694(0.318-1.51)$ & 0.358 \\
\hline Indomethacin & $151(46)$ & $11(39)$ & $0.767(0.348-1.69)$ & 0.510 \\
\hline Hypotension, age $<4$ d & $92(27)$ & $12(41)$ & $1.857(0.854-4.03)$ & 0.119 \\
\hline Histologic chorioamnionitis* & $127(69)$ & $7(54)$ & $0.524(0.178-1.44)$ & 0.202 \\
\hline Fetal vasculitis* & $104(57)$ & $4(31)$ & $0.338(0.100-1.136)$ & 0.079 \\
\hline Ureaplasma colonization & $114(34)$ & $16(55)$ & $2.43(1.13-5.22)$ & 0.023 \\
\hline Cord serum IL-6 (pg/mL) †, median (IQR) & $27.7(6.9-163.2)$ & $27.8(5.69-280.8)$ & $1.00(0.99-1.00)$ & 0.925 \\
\hline Cord serum IL- $1 \beta(\mathrm{pg} / \mathrm{mL}) \dagger$, median (IQR) & $0.619(0-4.873)$ & $0(0-0.977)$ & $0.967(0.87-1.01)$ & 0.54 \\
\hline
\end{tabular}

Values are presented as $n(\%)$ and mean \pm SD.

* Placentas were available for review in 197 subjects in cohort 1 .

$\dagger$ Cord serum samples were available from 101 subjects in cohort 1 .

IQR, interquartile range; POL, preterm onset labor; PPROM, preterm premature rupture of membranes; PDA, patent ductus arteriosus. 
Table 2. Obstetric and neonatal characteristics of study cohort

\begin{tabular}{|c|c|c|c|c|c|c|}
\hline \multirow[b]{2}{*}{ Variables } & \multicolumn{3}{|c|}{ NEC negative $(N=339)$} & \multicolumn{3}{|c|}{ NEC positive $(N=29)$} \\
\hline & $\begin{array}{l}\text { Ureaplasma (-) } \\
\quad(N=225)\end{array}$ & $\begin{array}{l}\text { Ureaplasma }(+) \\
\quad(N=114)\end{array}$ & $p$ & $\begin{array}{c}\text { Ureaplasma }(-) \\
\quad(N=13)\end{array}$ & $\begin{array}{c}\text { Ureaplasma }(+) \\
\quad(N=16)\end{array}$ & $p$ \\
\hline Birth weight $(\mathrm{g})$, mean $\pm \mathrm{SD}$ & $1059 \pm 355$ & $945 \pm 334$ & 0.004 & $1060 \pm 363$ & $848 \pm 168$ & 0.048 \\
\hline $\mathrm{GA}(\mathrm{wk})$, mean $\pm \mathrm{SD}$ & $27.8 \pm 3$ & $26.3 \pm 4.2$ & $<0.001$ & $28.2 \pm 2$ & $26 \pm 2$ & 0.005 \\
\hline Males & $114(51)$ & $64(56)$ & 0.340 & $11(85)$ & $8(50)$ & 0.051 \\
\hline Black race & $153(68)$ & $76(67)$ & 0.504 & $11(85)$ & $10(63)$ & 0.396 \\
\hline POL & $167(75)$ & $99(87)$ & 0.009 & $7(54)$ & $14(88)$ & 0.044 \\
\hline PPROM & $76(34)$ & $69(61)$ & $<0.001$ & $3(23)$ & $10(63)$ & 0.034 \\
\hline $\mathrm{ROM}<1 \mathrm{~h}$ & $107(48)$ & $33(29)$ & 0.001 & $8(62)$ & $5(31)$ & 0.103 \\
\hline $\mathrm{PIH}$ & $35(16)$ & $4(4)$ & 0.001 & $3(23)$ & 0 & 0.042 \\
\hline Clinical chorioamnionitis & $47(21)$ & $33(30)$ & 0.070 & $1(8)$ & $6(43)$ & 0.049 \\
\hline Maternal antibiotics & $158(70)$ & $101(89)$ & $<0.001$ & $7(54)$ & $15(94)$ & 0.013 \\
\hline Cesarean section & $133(59)$ & $52(46)$ & 0.018 & $9(69)$ & $8(50)$ & 0.296 \\
\hline PDA & $119(54)$ & $55(48)$ & 0.331 & $3(25)$ & $9(56)$ & 0.098 \\
\hline Indomethacin & $102(47)$ & $49(44)$ & 0.600 & $3(25)$ & $8(50)$ & 0.180 \\
\hline Late-onset sepsis & $71(32)$ & $38(34)$ & 0.761 & $9(75)$ & $9(56)$ & 0.306 \\
\hline Hypotension $<4 \mathrm{~d}$ age & $58(26)$ & $34(30)$ & 0.502 & $5(38)$ & $7(44)$ & 0.774 \\
\hline IMV (d), median (IQR) & $4(0-21)$ & $12(0-34)$ & 0.037 & $9(5-16)$ & $25(10-38)$ & 0.087 \\
\hline Supplemental oxygen (d), median (IQR) & $30(5-55)$ & $52(4-77)$ & 0.0084 & $34(23-50)$ & $36(22-77)$ & 0.661 \\
\hline BPD at 36 wk PMA & $49(23)$ & $39(35)$ & 0.21 & $4(31)$ & $6(43)$ & 0.516 \\
\hline Length of stay (d), median (IQR) & $52(38-74)$ & $73(36-92)$ & 0.006 & $87(67-118)$ & $85(52-115)$ & 0.443 \\
\hline Survival & $210(95)$ & $110(97)$ & 0.538 & $11(85)$ & $11(69)$ & 0.321 \\
\hline Death age (d), median (IQR) & $15(7-43)$ & $11(9-12)$ & 0.391 & $25(23-26)$ & $21(19-39)$ & 0.696 \\
\hline
\end{tabular}

Values are presented as $n(\%)$ and mean $\pm \mathrm{SD}$.

IMV, intermittent mechanical ventilation; IQR, interquartile range; POL, preterm onset labor; PPROM, preterm premature rupture of membranes; ROM, rupture of membranes; PIH, pregnancy-induced hypertension; PDA, patent ductus arteriosus; PMA, postmenstrual age.

they developed NEC (Table 2). The birth weights of Ureaplasmapositive infants were lower than the birth weights of the Ureaplasma-negative infants in the non-NEC group. However, the incidence of NEC was 2.1-fold higher in Ureaplasma-positive $(12.3 \%)$ than Ureaplasma-negative infants $(5.5 \%)<33 \mathrm{wk}(\mathrm{OR}$, 2.43; 95\% CI, 1.13-5.22; $p=0.023$; Table 1) and 3.3-fold higher in Ureaplasma-positive (14.6\%) than Ureaplasma-negative (4.4\%) infants $\leq 28$ wks (OR, 3.67; 95\%CI, 1.36-9.93). When adjusted for GA, the association of Ureaplasma colonization and NEC remained significant (OR, 2.47; 95\% CI, 1.13-5.43). Inclusion of other clinical variables in the logistics model did not affect the estimate of the association of Ureaplasma colonization and NEC. There were no differences in NEC rates between the Ureaplasma species. Age of onset, hematologic parameters at onset, NEC severity, and mortality were similar between Ureaplasmapositive and -negative NEC infants (Table 3). All Ureaplasmapositive NEC infants had been fed before onset compared with 92\% Ureaplamsa-negative NEC infants, but this difference was not statistically significant.

Inflammatory markers associated with NEC in Ureaplasmacolonized VLBW infants. As shown in Table 4, Ureaplasmacolonized infants had significantly higher admission peripheral white blood cell counts and absolute neutrophil counts regardless of NEC status. Although histologic chorioamnionitis was present in $92 \%$ placentas from Ureaplasma nonNEC and $100 \%$ Ureaplasma NEC infants, inflammation was detected in 1 of 7 (14\%) placentas from Ureaplasma-negative NEC infants $(p=0.052)$. Similarly, fetal vasculitis was present in $79 \%$ placentas from Ureaplasma non-NEC and 67\% Ureaplasma NEC infants but absent in all placentas available for review from Ureaplasma-negative NEC infants. When restricted to the subset with placental pathology, histo-
Table 3. Characteristics of NEC infants with and without Ureaplasma respiratory tract colonization

\begin{tabular}{lccc}
\hline & $\begin{array}{c}\text { Ureaplasma }(-) \\
(N=13)\end{array}$ & $\begin{array}{c}\text { Ureaplasma }(+) \\
(N=16)\end{array}$ & $p$ \\
\hline $\begin{array}{l}\text { Age of onset, d, } \\
\text { mean } \pm \text { SD }\end{array}$ & $22.2 \pm 10.5$ & $29.3 \pm 19.4$ & 0.246 \\
Presence of feeds & $12(92)$ & $15(100)$ & 0.448 \\
Medical NEC & $2(15)$ & $7(44)$ & 0.101 \\
$\begin{array}{l}\text { Surgical NEC } \\
\text { WBC } \times 10^{3} \text { at NEC } \\
\text { onset, mean } \pm \text { SD }\end{array}$ & $11(85)$ & $9(56)$ & \\
Platelets $\times 10^{6}$ at NEC & $244 \pm 18.3$ & $12.8 \pm 7.8$ & 0.122 \\
$\quad$ onset, mean \pm SD & & $286 \pm 178$ & 0.557 \\
\hline
\end{tabular}

Values are presented as $n(\%)$ and mean $\pm \mathrm{SD}$.

WBC, white blood cell count.

logic chorioamnionitis in the absence of Ureaplasma colonization tended to reduce the risk for NEC (OR, 0.524; 95\% CI, $0.178-1.44 ; p=0.202$ ). Because Ureaplasma colonization rarely occurred in the absence of histologic chorioamnionitis, it was not possible to distinguish the relative contribution of each variable to NEC.

Cord serum cytokine measurements were available for 101 of 232 (44\%) subjects of cohort 1 . Cord serum IL-6 and IL- $1 \beta$ concentrations were similar in NEC and non-NEC groups (Table 1) but were significantly higher in Ureaplasmapositive than in Ureaplasma-negative infants. The highest cytokine concentrations were detected in cord blood samples of Ureaplasma-positive NEC infants (Table 4).

\section{DISCUSSION}

The two cohorts experienced similar rates of NEC, suggesting that the rate of the disease has been stable in our NICUs 
Table 4. Markers of inflammation in infants with and without NEC

\begin{tabular}{|c|c|c|c|c|c|c|}
\hline \multirow[b]{2}{*}{ Variables } & \multicolumn{3}{|c|}{ NEC negative $(N=340)$} & \multicolumn{3}{|c|}{ NEC positive $(N=29)^{*}$} \\
\hline & $\begin{array}{c}\text { Ureaplasma }(-) \\
\quad(N=225)\end{array}$ & $\begin{array}{c}\text { Ureaplasma }(+) \\
\quad(N=114)\end{array}$ & $p$ & $\begin{array}{c}\text { Ureaplasma }(-) \\
\qquad(N=13)\end{array}$ & $\begin{array}{c}\text { Ureaplasma }(+) \\
\quad(N=16)\end{array}$ & $p$ \\
\hline Admission $\mathrm{WBC} \times 10^{3}$, mean $\pm \mathrm{SD}$ & $11 \pm 9.0$ & $19.4 \pm 16.1$ & $<0.001$ & $5.2 \pm 2.4$ & $16.7 \pm 9.4$ & $<0.001$ \\
\hline Admission $\mathrm{ANC} \times 10^{3}$, mean $\pm \mathrm{SD}$ & $5.37 \pm 6.48$ & $10.53 \pm 1.18$ & $<0.001$ & $1.75 \pm 1.16$ & $8.73 \pm 6.51$ & 0.0007 \\
\hline Histologic chorioamnionitis, $n(\%) \dagger$ & $68(56)$ & $58(92)$ & $<0.001$ & $1(14)$ & $6(100)$ & 0.052 \\
\hline Fetal vasculitis, $n(\%)$ & $55(45)$ & $49(79)$ & $<0.001$ & 0 & $4(67)$ & 0.009 \\
\hline Cord serum IL-6 (pg/mL), médian (IQR) $\ddagger$ & $13.2(0.73-1098)$ & $86.8(5.9-1040)$ & $<0.001$ & $7.89(1-280.8)$ & $297(185-1916)$ & 0.039 \\
\hline Cord serum IL- $1 \beta(\mathrm{pg} / \mathrm{mL})$, median (IQR) & $0.23(0-47.9)$ & $1.91(0-40.7)$ & 0.003 & $0(0-0.3)$ & $10.4(1.7-19.2)$ & 0.022 \\
\hline
\end{tabular}

* WBC and ANC data are derived from combined cohorts 1 and 2; placental pathology and cord cytokine data are derived from cohort 1 only.

$\uparrow$ Placentas were available for review in 197 subjects in cohort 1 .

\$ Cord serum samples were available from 101 subjects in cohort 1 .

WBC, white blood cell count; ANC, absolute neutrophil count; IQR, interquartile range.

over time. The overall rate of $7.9 \%$ is within the range of confirmed NEC rates for VLBW infants reported by the National Institute of Child Health and Human Development Neonatal Research Network (10.1\%) (1) and the Vermont Oxford Network (6.9\%) (2).

Because NEC is primarily a disease of prematurity, immaturity of gut barrier function and local and systemic immune responses have been implicated in susceptibility to the disease. Recently, more attention has focused on the potential role of the intestinal microbiota in initiating mucosal injury and modulating expression of virulence factors and host immune responses (29). Although many bacterial species and enteric viruses have been reported in association with NEC (29), a causal role for these organisms has not been established. This is the first study to demonstrate an association of Ureaplasma respiratory tract colonization and NEC. Although Ureaplasma was only cultured from respiratory secretions, Ureaplasma spp. are known mucosal organisms that colonize the adult genitourinary tract (10) and have been previously recovered from other mucosal sites such as gastric aspirates and rectum in preterm infants $(21,30)$. The observed higher rate of NEC in Ureaplasma-positive than negative infants $\leq 28 \mathrm{wk}$ gestation supports the contention that immaturity of intestinal functions increases the susceptibility to NEC in very preterm infants perinatally exposed to Ureaplasma infection/inflammation.

Using culture techniques, Ureaplasma spp. have been isolated from blood, cerebrospinal fluid, tracheal aspirates, and lung and brain tissue of newborn infants (11,31-33). Epidemiologic studies and experimental infection models support an etiologic role for Ureaplasma infection or resulting inflammation in preterm birth and several neonatal morbidities. Although the association of Ureaplasma respiratory tract colonization with the development of BPD in preterm infants has been debated, a recent meta-analysis of 31 studies supported this association (34). Experimental antenatal infection models in mice (35), immature sheep (36), Rhesus macaque (37), and baboon (17) confirm that in utero exposure to Ureaplasma infection causes fetal/newborn lung inflammation and altered lung development. In our first study of cohort 1, we observed that Ureaplasma species not only colonize the respiratory tract but also invade the bloodstream and cross the immature blood-brain barrier in 23\% VLBW infants (24). Detection of Ureaplasma by PCR in serum, but not cerebrospinal fluid, increased the risk for severe intraventricular hemorrhage 2 -fold (24). In a mouse model of antenatal Ureaplasma infection, neuronal injury and microgliosis were evident in Ureaplasma antenatally infected pups (35).

There is compelling data from human studies and animal models that Ureaplasma is proinflammatory in multiple compartments (amniotic fluid, placenta, fetal lung, and brain). The stimulatory effect of Ureaplasma on cytokine release has been confirmed in vitro. In cultured human cord blood preterm monocytes, Ureaplasma stimulated release of TNF- $\alpha$ and IL-8, and when coadministered with Gram-negative lipopolysaccharide, Ureaplasma greatly augmented generation of proinflammatory cytokines while blocking expression of the counter regulatory cytokines, IL-6 and IL-10 (15). In the current study, Ureaplasma-positive infants were more likely exposed to chorioamnionitis and to express a systemic inflammatory response (fetal vasculitis, elevated admission white blood cell and absolute neutrophil counts, and cord blood IL-6 and IL-1 $\beta$ ), suggesting that inflammation was initiated in utero. This is consistent with recent evidence that in the setting of preterm premature rupture of membranes, intraamniotic infection with the genital mycoplasmas is associated with a more intense inflammatory response compared with the response to infections with other microorganisms (38). Antenatal exposure to infection/inflammation may predispose the developing intestinal mucosa to subsequent injury or dysregulated inflammatory responses. Previous studies have linked presence of amniotic fluid infection/elevated cytokines (39), cord blood cytokines $(40,41)$, and fetal vasculitis (42) with risk for NEC in preterm infants. In a rat model of NEC, maternal prenatal exposure to lipopolysaccharide led to increased frequency and severity of intestinal injury (43). Taken together, these observations suggest that intestinal injury may be initiated in utero. Hematologic parameters and postnatal age at NEC onset did not differ between Ureaplasma-positive and -negative infants, suggesting that other postnatal factors are necessary for disease progression such as initiation of enteral feeds, prolonged exposure to antibiotics (44) or H2blockers (45), or change in the intestinal microbiome.

There are several limitations of this study. Ureaplasma respiratory tract colonization in the first week of life was used as a proxy for intestinal mucosal exposure to this organism. Because the primary outcomes of the studies analyzed for this 
report were BPD and CNS outcomes, cultures were not obtained at the time of NEC onset. We also cannot exclude that infants were exposed antenatally to other microbes that may have altered intestinal permeability or the local immune response (46). Although the duration of ruptured membranes exceeded $1 \mathrm{~h}$ in the majority of Ureaplasma-positive infants, indicating vertical transmission likely occurred via an ascending infection, the duration of exposure to the organism before delivery is unknown. Bacterial load of Ureaplasma that correlates with severity of intrauterine inflammation $(47,48)$ may be an important variable that was not measured in the current study.

Whether there is a causal relationship between perinatal Ureaplasma colonization/infection and NEC pathogenesis is currently unknown, but this can be addressed in in vitro and animal NEC models in future studies. Molecular methods may improve the detection of these organisms in relevant specimens such as gastric aspirates, stool, and surgical specimens (22) to confirm this association.

This study identifies Ureaplasma respiratory tract colonization, a marker of in utero infection/inflammation exposure, as a possible risk factor for NEC in VLBW infants. Whether Ureaplasma directly contributes to intestinal mucosal injury or alters the local immune response is unknown. Future experimental cell and animal models may determine how Ureaplasma contributes to NEC pathogenesis.

Acknowledgments. We thank Elise Janofsky and Mary Spence for their technical assistance and data abstraction, and Lynn Duffy, Department of Pathology, University of Alabama at Birmingham, Birmingham, AL, for technical assistance.

\section{REFERENCES}

1. Uauy RD, Fanaroff AA, Korones SB, Phillips EA, Phillips JB, Wright LL 1991 Necrotizing enterocolitis in very low birth weight infants: biodemographic and clinical correlates. National Institute of Child Health and Human Development Neonatal Research Network. J Pediatr 119:630-638

2. Fitzgibbons SC, Ching Y, Yu D, Carpenter J, Kenny M, Weldon C, Lillehei C, Valim C, Horbar JD, Jaksic T 2009 Mortality of necrotizing enterocolitis expressed by birth weight categories. J Pediatr Surg 44:1072-1075; discussion 1075-1076

3. Viscardi RM, Lyon NH, Sun C-C, Hebel JR, Hasday JD 1997 Inflammatory cytokine mRNAs in surgical specimens of necrotizing enterocolitis and normal newborn intestine. Pediatr Pathol Lab Med 17:547-559

4. Caplan MS, Lickerman M, Adler L, Dietsch GN, Yu A 1997 The role of recombinant platelet-activating factor acetylhydrolase in a neonatal rat model of necrotizing enterocolitis. Pediatr Res 42:779-783

5. Edelson MB, Bagwell CE, Rozycki HJ 1999 Circulating pro- and counterinflammatory cytokine levels and severity in necrotizing enterocolitis. Pediatrics 103:766771

6. Halpern MD, Holubec H, Dominguez JA, Williams CS, Meza YG, McWilliam DL, Payne CM, McCuskey RS, Besselsen DG, Dvorak B 2002 Up-regulation of IL-18 and IL-12 in the ileum of neonatal rats with necrotizing enterocolitis. Pediatr Res 51:733-739

7. Harris MC, D'Angio CT, Gallagher PR, Kaufman D, Evans J, Kilpatrick L 2005 Cytokine elaboration in critically ill infants with bacterial sepsis, necrotizing entercolitis, or sepsis syndrome: correlation with clinical parameters of inflammation and mortality. J Pediatr 147:462-468

8. Seitz G, Warmann SW, Guglielmetti A, Heitmann H, Ruck P, Kreis ME, Fuchs J 2005 Protective effect of tumor necrosis factor alpha antibody on experimental necrotizing enterocolitis in the rat. J Pediatr Surg 40:1440-1445

9. van Waarde WM, Brus F, Okken A, Kimpen JL 1997 Ureaplasma urealyticum colonization, prematurity and bronchopulmonary dysplasia. Eur Respir J 10:886890

10. Waites KB, Katz B, Schelonka RL 2005 Mycoplasmas and ureaplasmas as neonatal pathogens. Clin Microbiol Rev 18:757-789

11. Goldenberg RL, Andrews WW, Goepfert AR, Faye-Petersen O, Cliver SP, Carlo WA, Hauth JC 2008 The Alabama Preterm Birth Study: umbilical cord blood Ureaplasma urealyticum and Mycoplasma hominis cultures in very preterm newborn infants. Am J Obstet Gynecol 198:43.e1-43.e5
12. Viscardi RM, Hasday JD 2009 Role of Ureaplasma species in neonatal chronic lung disease: epidemiologic and experimental evidence. Pediatr Res 65:84R-90R

13. Patterson AM, Taciak V, Lovchik J, Fox RE, Campbell AB, Viscardi RM 1998 Ureaplasma urealyticum respiratory tract colonization is associated with an increase in interleukin 1-beta and tumor necrosis factor alpha relative to interleukin 6 in tracheal aspirates of preterm infants. Pediatr Infect Dis J 17:321-328

14. Viscardi RM, Manimtim WM, Sun CC, Duffy L, Cassell GH 2002 Lung pathology in premature infants with Ureaplasma urealyticum infection. Pediatr Dev Pathol 5:141-150

15. Manimtim WM, Hasday JD, Hester L, Fairchild KD, Lovchik JC, Viscardi RM 2001 Ureaplasma urealyticum modulates endotoxin-induced cytokine release by human monocytes derived from preterm and term newborns and adults. Infect Immun 69:3906-3915

16. Viscardi RM, Kaplan J, Lovchik JC, He JR, Hester L, Rao S, Hasday JD 2002 Characterization of a murine model of Ureaplasma urealyticum pneumonia. Infect Immun 70:5721-5729

17. Yoder BA, Coalson JJ, Winter VT, Siler-Khodr T, Duffy LB, Cassell GH 2003 Effects of antenatal colonization with Ureaplasma urealyticum on pulmonary disease in the immature baboon. Pediatr Res 54:797-807

18. Viscardi RM, Atamas SP, Luzina IG, Hasday JD, He JR, Sime PJ, Coalson JJ, Yoder BA 2006 Antenatal Ureaplasma urealyticum respiratory tract infection stimulates proinflammatory, profibrotic responses in the preterm baboon lung. Pediatr Res 60:141-146

19. Wang EE, Frayha H, Watts J, Hammerberg O, Chernesky MA, Mahony JB, Cassell GH 1988 Role of Ureaplasma urealyticum and other pathogens in the development of chronic lung disease of prematurity. Pediatr Infect Dis J 7:547-551

20. Taylor-Robinson D, Furr PM, Liberman MM 1984 The occurrence of genital mycoplasmas in babies with and without respiratory distress. Acta Paediatr Scand 73:383-386

21. Sánchez PJ, Regan JA 1990 Vertical transmission of Ureaplasma urealyticum from mothers to preterm infants. Pediatr Infect Dis J 9:398-401

22. Jones V, Wilks M, Johnson G, Warwick S, Hennessey E, Kempley S, Millar M 2010 The use of molecular techniques for bacterial detection in the analysis of gastric aspirates collected from infants on the first day of life. Early Hum Dev 86:167-170

23. Viscardi RM, Muhumuza CK, Rodriguez A, Fairchild KD, Sun CC, Gross GW, Campbell AB, Wilson PD, Hester L, Hasday JD 2004 Inflammatory markers in intrauterine and fetal blood and cerebrospinal fluid compartments are associated with adverse pulmonary and neurologic outcomes in preterm infants. Pediatr Res 55:1009-1017

24. Viscardi RM, Hashmi N, Gross GW, Sun CC, Rodriguez A, Fairchild KD 2008 Incidence of invasive ureaplasma in VLBW infants: relationship to severe intraventricular hemorrhage. J Perinatol 28:759-765

25. Bell MJ, Ternberg JL, Feigin RD, Keating JP, Marshall R, Barton L, Brotherton T 1978 Neonatal necrotizing enterocolitis. Therapeutic decisions based upon clinical staging. Ann Surg 187:1-7

26. Shepard MC 1983 Culture media for Ureaplasmas. In: Razin S, Tully JG (eds) Methods in Mycoplasmology. Vol 1 Academic Press, New York, pp 137-146

27. Xiao L, Glass JI, Paralanov V, Yooseph S, Cassell GH, Duffy LB, Waites KB 2010 Detection and characterization of human Ureaplasma species and serovars by real-time PCR. J Clin Microbiol 48:2715-2723

28. Redline RW, Wilson-Costello D, Borawski E, Fanaroff AA, Hack M 1998 Placental lesions associated with neurologic impairment and cerebral palsy in very low-birthweight infants. Arch Pathol Lab Med 122:1091-1098

29. Morowitz MJ, Poroyko V, Caplan M, Alverdy J, Liu DC 2010 Redefining the role of intestinal microbes in the pathogenesis of necrotizing enterocolitis. Pediatrics 125:777-785

30. Sánchez PJ, Regan JA 1988 Ureaplasma urealyticum colonization and chronic lung disease in low birth weight infants. Pediatr Infect Dis J 7:542-546

31. Waites KB, Crouse DT, Cassell GH 1993 Systemic neonatal infection due to Ureaplasma urealyticum. Clin Infect Dis 17:S131-S135

32. Ollikainen J, Hiekkaniemi H, Korppi M, Katila ML, Heinonen K 1993 Ureaplasma urealyticum cultured from brain tissue of preterm twins who died of intraventricular hemorrhage. Scand J Infect Dis 25:529-531

33. Ollikainen J, Hiekkaniemi H, Korppi M, Sarkkinen H, Heinonen K 1993 Ureaplasma urealyticum infection associated with acute respiratory insufficiency and death in premature infants. J Pediatr 122:756-760

34. Schelonka RL, Katz B, Waites KB, Benjamin DK Jr 2005 Critical appraisal of the role of Ureaplasma in the development of bronchopulmonary dysplasia with metaanalytic techniques. Pediatr Infect Dis J 24:1033-1039

35. Normann E, Lacaze-Masmonteil T, Eaton F, Schwendimann L, Gressens P, Thebaud B 2009 A novel mouse model of Ureaplasma-induced perinatal inflammation: effects on lung and brain injury. Pediatr Res 65:430-436

36. Moss TJ, Knox CL, Kallapur SG, Nitsos I, Theodoropoulos C, Newnham JP, Ikegami M, Jobe AH 2008 Experimental amniotic fluid infection in sheep: effects of Ureaplasma parvum serovars 3 and 6 on preterm or term fetal sheep. Am J Obstet Gynecol 198:122.e1-122.e8

37. Novy MJ, Duffy L, Axthelm MK, Sadowsky DW, Witkin SS, Gravett MG, Cassell GH, Waites KB 2009 Ureaplasma parvum or Mycoplasma hominis as sole pathogens cause chorioamnionitis, preterm delivery, and fetal pneumonia in rhesus macaques. Reprod Sci 16:56-70

38. Oh KJ, Lee KA, Sohn YK, Park CW, Hong JS, Romero R, Yoon BH 2010 Intraamniotic infection with genital mycoplasmas exhibits a more intense inflammatory response than intraamniotic infection with other microorganisms in patients with preterm premature rupture of membranes. Am J Obstet Gynecol 203:211.e1211.e8 
39. Hitti J, Tarczy-Hornoch P, Murphy J, Hillier SL, Aura J, Eschenbach DA 2001 Amniotic fluid infection, cytokines, and adverse outcome among infants at 34 weeks' gestation or less. Obstet Gynecol 98:1080-1088

40. Weeks JW, Reynolds L, Taylor D, Lewis J, Wan T, Gall SA 1997 Umbilical cord blood interleukin-6 levels and neonatal morbidity. Obstet Gynecol 90:815-818

41. Goepfert AR, Andrews WW, Carlo W, Ramsey PS, Cliver SP, Goldenberg RL, Hauth JC 2004 Umbilical cord plasma interleukin-6 concentrations in preterm infants and risk of neonatal morbidity. Am J Obstet Gynecol 191:1375-1381

42. Andrews WW, Goldenberg RL, Faye-Petersen O, Cliver S, Goepfert AR, Hauth JC 2006 The Alabama Preterm Birth study: polymorphonuclear and mononuclear cell placental infiltrations, other markers of inflammation, and outcomes in 23- to 32-week preterm newborn infants. Am J Obstet Gynecol 195:803-808

43. Giannone PJ, Nankervis CA, Richter JM, Schanbacher BL, Reber KM 2009 Prenatal lipopolysaccharide increases postnatal intestinal injury in a rat model of necrotizing enterocolitis. J Pediatr Gastroenterol Nutr 48:276-282

44. Cotten CM, Taylor S, Stoll B, Goldberg RN, Hansen NI, Sanchez PJ, Ambalavanan N, Benjamin DK Jr 2009 Prolonged duration of initial empirical antibiotic treatment is associated with increased rates of necrotizing enterocolitis and death for extremely low birth weight infants. Pediatrics 123:58-66

45. Guillet R, Stoll BJ, Cotten CM, Gantz M, McDonald S, Poole WK, Phelps DL 2006 Association of H2-blocker therapy and higher incidence of necrotizing enterocolitis in very low birth weight infants. Pediatrics 117:e137-e142

46. Onderdonk AB, Hecht JL, McElrath TF, Delaney ML, Allred EN, Leviton A 2008 Colonization of second-trimester placenta parenchyma. Am J Obstet Gynecol 199:52.e1-52.e10

47. Jacobsson B, Aaltonen R, Rantakokko-Jalava K, Morken NH, Alanen A 2009 Quantification of Ureaplasma urealyticum DNA in the amniotic fluid from patients in PTL and pPROM and its relation to inflammatory cytokine levels. Acta Obstet Gynecol Scand 88:63-70

48. Kasper DC, Mechtler TP, Reischer GH, Witt A, Langgartner M, Pollak A, Herkner KR, Berger A 2010 The bacterial load of Ureaplasma parvum in amniotic fluid is correlated with an increased intrauterine inflammatory response. Diagn Microbiol Infect Dis 67:117-121 